\title{
Chapter 7 \\ Navigating Service Design Tools Using the Map of Capabilities
}

\begin{abstract}
This is a navigation chapter, with the aim of providing a logical frame to summarise the design capabilities at all the levels described in the previous chapters. The reader can use the navigation framework suggested in this chapter to create their own operational paradigm or as a way to use the various tools and toolboxes available in service design literature.
\end{abstract}

The previous chapters provided an overview of design capability in relation to the levels of design intervention. The aim was to give an understanding of the value of service design and design action in the evolution of contemporary society and provide a view with different lenses - from the details of everyday life to the broader overview needed to understand and possibly orient societal change.

As a profession, service design today is becoming more and more relevant, and the offering for service design education (Becermen and Simeone 2019, 2020) and training tools ${ }^{1}$ is increasing. However, the characterisation of the professional role of service designers in various aspects of society is nevertheless quite underdefined. Evidence of this is in how few calls for positions in the public or private sector mention service design as a specific professional profile. While companies or public institutions have a very clear idea of what a medical doctor, or an architect, or a lawyer can do-and they understand the specialisations within their professional area-the demand for service designers is hidden behind other job titles, such as interaction designer, UX designer, and experience designer. It is not that these titles are better defined, but they do have the advantage of being referred to in very specific phases of the development of a new product or service (Ehn et al. 2020).

A professional area is recognised once its practices are defined and implicitly or explicitly codified. And when a toolbox is defined, it specifically refers to those practices. The codification of practices is a long and complex process based on the exchange of academic knowledge and the transmission of such knowledge through

\footnotetext{
${ }^{1}$ New initiatives are emerging that provide training opportunities to include design as a diffuse capability. Among them, the Designscapes project is developing a series of training modules for Design-Enabled Innovation in the urban context, with the support of a critical overview of some key tools (Designscapes.eu).
} 
education and training. This is in fact what the growing number of academic education programmes in service design are currently effecting.

Defining a practice for service design means developing an operative paradigm (Arbnor and Bjerke 1997) — a specific conceptual and operational toolbox for service designers-which includes tools, methods, examples, cases, techniques borrowed and adapted from other disciplines, and anything else that may constitute a service design expertise. This activity is mostly developed through academic or professional conferences and publications, and is facilitated by the increasing number of toolkits available in the relevant literature and online publications.

The abundance of methods and tools available for service designers may inspire a cookbook approach, as in, an approach in which, given the problem to solve, it is possible to find a recipe (a method or a tool) that supports designers in finding the solution to the problem. However, the reality is far from being that easy, for three main reasons:

1. The number of methods and tools available in the various sources is wide enough to confuse an inexperienced service designer or a student.

2. Although the utilisation of tools and methods concerns the way designers address operative aspects, the way such methods and tools are used strongly depends on the designer's methodological approach. This, in turn, depends on each individual designer's attitude towards the interpretation of reality (their ultimate presumptions) and on the influence of the socio-technical landscape in which the designer operates.

3. There is no direct or unequivocal correspondence between a problem to solve and the tools that can be used to solve it.

The first point would require each individual designer to acquire their own navigation experience among the tools and the knowledge available to face operative tasks. Today, a number of toolkits are currently available, some of which serve as a reference for students and service design practitioners (Stickdorn and Schneider 2011; Stickdorn et al. 2018; Servicedesigntools.org; Polaine and Løvlie 2013). Service design practice is also consolidated through the acquisition of methods, tools and expertise from other academic or practice-related areas, such as social studies, anthropology, engineering or management studies. Therefore, other toolkits have been used in service design practice that originate from social innovation (Kimbell 2013b), service innovation (Kimbell 2013a), or studies on design and creativity (Sanders and Stappers 2012). The point is that the existence of so many tools does not define per se a practice of service design, just as the existence of a hardware store does not necessarily imply the existence of a plumber or a locksmith.

The second point would require designers to define their conceptual position in respect to the tasks they are required to perform. The same problem could be solved through a massive use of technology or through an approach that privileges customers' engagement, participation or collective intelligence. It can be grounded on a collective initiative (bottom-up) or from decision-making centres (top-down). This is valid for broad social problems, such as the shift to a circular economy, and in minimal interactions, such as the way people interact with their bank. The two 
approaches would lead towards different actions, and consequently, to the use of different tools: a technology-oriented approach to regulate the interaction between banks and their clients would suggest a prescriptive attitude, in which the action of the various actors in the service is supposed to follow a procedure specified by a blueprint or by rigidly defined use cases. A participatory approach to the same kind of interaction would be based on providing as much information as possible to the customer in order to create some expectations that would support a more collaborative approach between the bank employee and the client.

The third point is a direct consequence of the first two-every problem can be seen from different perspectives and therefore can be solved through the use of different tools. And the same tool can be used to solve different problems in different phases of the design process.

\subsection{Towards an Operative Paradigm}

The definition of an operative paradigm is the process of the progressive accumulation of personal experience and knowledge that allows service designers to navigate between a number of problem areas using the most adequate tools and methods. Such tools and methods are often adapted from other disciplines and incorporated into the everyday practice of service designers. The various toolkits and design manuals available in the literature support the process of adapting different tools and methods to the process of service design. The navigation and use of such tools in design practice is instead related to the methodological approach, especially considering the operative tasks designers usually have in a design process. This book starts with the observation that the proliferation of toolkits is not accompanied by a corresponding proliferation of critical contributions to create an operative paradigm. To fill this gap, this book proposes a framework, starting from a classification of tools for service designers according to three main categories of tasks (Morelli and Tollestrup 2007):

- The analysis and interpretation of the context for the design action (analytical tools): in this area, tools are included that help the designer/design teams to understand the context of design action. This includes the identification of the main actors, the analysis of specific and personal profiles, and the identification of socio-technical conditions of the context.

- The development of new solutions (design tools): this area includes tools to not only articulate new solutions and define the relation between such solutions but also engage users and facilitate creative problem-solving processes.

- The representation and communication of the new solutions among the stakeholders in the value creation process (representation tools): this area includes tools to support not only a shared understanding of the roles and interaction in a service but also visions and the ability to mediate the collaboration among stakeholders. 
Table 7.1 Overview of design capabilities and tasks at different logical levels

\begin{tabular}{|c|c|c|c|}
\hline \multirow{2}{*}{$\begin{array}{l}\text { Levels of } \\
\text { interventions }\end{array}$} & \multicolumn{3}{|l|}{ Category of tasks } \\
\hline & Analysing & Designing & Representing \\
\hline Service as interaction & $\begin{array}{l}\text { Addressing the } \\
\text { context } \\
\text { Identifying } \\
\text { stakeholders } \\
\text { Identifying relevant } \\
\text { issues } \\
\text { Analysing complex } \\
\text { contexts/routinary } \\
\text { behaviours } \\
\text { Engaging } \\
\text { stakeholders } \\
\text { Supporting } \\
\text { conversation }\end{array}$ & $\begin{array}{l}\text { Controlling } \\
\text { experiential aspects } \\
\text { Prototyping } \\
\text { Experiments } \\
\text { Engaging } \\
\text { stakeholders } \\
\text { Supporting } \\
\text { participation } \\
\text { Modelling } \\
\text { Co-designing solutions } \\
\text { Facilitating creative } \\
\text { problem-solving }\end{array}$ & $\begin{array}{l}\text { Vision building } \\
\text { Inspiring participants } \\
\text { Generating scenarios }\end{array}$ \\
\hline $\begin{array}{l}\text { Service as } \\
\text { infrastructure }\end{array}$ & $\begin{array}{l}\text { Addressing the } \\
\text { context } \\
\text { Analysing } \\
\text { stakeholders' } \\
\text { networks } \\
\text { Analysing } \\
\text { motivations }\end{array}$ & $\begin{array}{l}\text { Building logical } \\
\text { architecture } \\
\text { Proposing service } \\
\text { architectures } \\
\text { Open } \\
\text { problem-solving } \\
\text { Creating platforms for } \\
\text { interaction }\end{array}$ & $\begin{array}{l}\text { Vision building } \\
\text { Visualising } \\
\text { organisational } \\
\text { structures } \\
\text { Building logical } \\
\text { architecture } \\
\text { Blueprinting services } \\
\text { Ecosystems maps }\end{array}$ \\
\hline $\begin{array}{l}\text { Service as systemic } \\
\text { institution }\end{array}$ & $\begin{array}{l}\text { Addressing the } \\
\text { context } \\
\text { Understanding } \\
\text { ecosystems and } \\
\text { power relations }\end{array}$ & $\begin{array}{l}\text { Modelling } \\
\text { Proposing business } \\
\text { models } \\
\text { Working across } \\
\text { different logical levels } \\
\text { Articulating missions }\end{array}$ & $\begin{array}{l}\text { Vision building } \\
\text { Generating } \\
\text { visions/scenarios }\end{array}$ \\
\hline
\end{tabular}

As mentioned, the use of such tools depends on the problem to solve, which will differ according to the scale of it, the interpretation of those who are addressing it, and the methodological approach of those who want to solve it. In particular, the levels defined in the previous chapter can help us identify specific tasks at each level (Table 7.1).

\subsubsection{Service as Interaction: Analytical Capabilities}

Addressing the context Identifying stakeholders and understanding their role in the context of the interaction (a single touchpoint or an event) is key here. This includes the analysis of stakeholders' competences and knowledge, and the main technological, cultural, political or natural issues that might shape the interaction. Certain tools can be used to address the context: 
- Mapping tools such as ecosystem or stakeholders maps - these tools provide an overview of the main elements of the context and their interaction.

- Narrative tools such as journeys, which highlight practices and routines or personas, thus providing information about behaviours and preferences.

Engaging stakeholders This implies understanding the nature of the interaction stakeholders may have in value co-creation. When designers have direct interaction with the users/beneficiaries of a service (design activism, co-creation sessions) they engage people, facilitate their problem-solving activities, and inspire them by using tools or boundary objects. To engage stakeholders, certain tools and methods can be used:

- 5 Whys: Asking why?-questions to a person or a working group can be a way to discover the deep motivations for their behaviour.

- Card sorting: This method is useful in analysing the context, as it can prompt discussions of important issues that may reveal relevant aspects of the context. Cards can be created out of pictures of the context or by using symbols and metaphors.

- User stories: These engage participants in narrative exercises that help them describe situations, interactions, routines and emotions.

In many other cases the designer may not be able to interact directly with the service beneficiary but can still trigger or support the value creation process by generating tools for conversations that help beneficiaries analyse the context or frame the problem. Such tools may include these two useful tools:

- Issue cards: These act as a support to the analysis of complex contexts or everyday routines by breaking down areas of complexity into simpler issues that can be analysed and discussed (see Fig. 4.1).

- Maps and templates: These serve as frameworks that simplify the analysis of a context or an issue by helping people identify relevant actors (e.g. stakeholders' maps), interaction and value creations (e.g. value network maps), or routines (e.g. journey maps).

\subsubsection{Service as Interaction: Design Capabilities}

Controlling experiential aspects This implies the use of the following:

- Prototypes or pretotypes, that can simulate certain functional aspects of possible solutions to test how they will shape the experience of the service. The definition of a prototype may vary, ranging from a very sketchy simulation of specific aspects (e.g. Mechanical Turks, service acting, video sketches) to complex and interactive aggregations of service components.

- Experiments, which are often placed in specific contexts, such as the urban context and based on a direct interaction between designers and other actors (such as 
citizens or service providers). Experiments will provoke or trigger conversations upon logical, ethical or experiential aspects of possible solutions (see Sect. 4.4.2).

Modelling This activity involves facilitating opportunities for co-creation, such as workshops, hackathons, co-design and co-creation sessions, and innovation jams. The tools and methods used in this case aim at supporting creativity, problem solving and meaning making, and include:

- Card sorting: Using cards to support discussions in a working group.

- Journey mapping: Engaging the working group in the construction of possible journeys, or a narrative that describes a solution in a way that can be later implemented.

- Prototyping: Generating rapid prototypes or models of possible solutions that can be used to enact a specific functionality and investigate its functional or emotional aspects (see Fig. 4.2).

\subsubsection{Service as Interaction: Representation Capabilities}

Vision building This capability is geared towards generating visions and highlighting perspectives that engage people into preferable scenarios and consequently orient present actions.

The role of designers in this case is to represent a future that is not yet visible. To accomplish this, designers can choose from certain narrative tools, such as:

- Tomorrow's headlines: creating the headline of a fictional newspaper article that describes a future event based on a possible scenario of the future.

- Journeys and storyboards: narrative, and often graphical, representation of a story in a possible/desirable future.

- Prototypes or video sketches: in addition to being a valid way for testing possible solutions, prototypes make it possible for people to imagine new lifestyles, new practices or new behaviours and therefore help align the visions and expectations of different actors.

\subsubsection{Service as Infrastructure: Analytical Capabilities}

Addressing the context This capability enables designers to analyse and interpret the ecosystem of the service that will support value creation. When working at the infrastructuring level, the analysis of the context needs to extend to stakeholders and contextual elements that may not be visible or relevant in single interactions. Here, as in the analysis of the level of 'service as interaction':

- Maps can be used to identify stakeholders and relevant components of the ecosystem, their role and their motivation. 
- Journeys or other narrative tools can be used to figure out sequences of actions and stakeholders' behaviours.

- Personas can be used to analyse human, behavioural or social aspects that shape the context.

\subsubsection{Service as Infrastructure: Design Capabilities}

Building logical architecture This is the capability to create frameworks or logical and organisational structures that identify the main stakeholders and their role in shaping the service ecosystem. While the design capabilities to support services as interaction for value creation consist of proposing, provoking or inspiring, designing at this level implies a clear definition of the structures of interaction. It could have a prescriptive character, for example, when it describes the conditions for a function to happen, and it may be specific to the point of defining minimal aspects, such as the time or the channel of an interaction.

This capability implies analytical work on time sequences, service ecosystems and service platforms. Therefore, certain tools are often used to support this capability:

- Tools to control time, which include use cases, service journeys and service blueprints, which analyse the sequence of actions, specifying the actors and pre/post conditions for each interaction.

- Tools to control interaction, such as touchpoint mapping, which create maps of the different interaction between services and their stakeholders or beneficiaries.

- Tools to map the ecosystem (ecosystem maps), which include synchronic representations ${ }^{2}$ of the actors in the ecosystem, including the flows of interaction (e.g. information or money exchange, physical movements) or indications about the actors' role, skills and contribution to the ecosystem.

Open problem solving Even when structures need to be created, the design of a service needs to take into consideration the fundamental principle that value is ultimately created by beneficiaries (Vargo and Lusch 2004, 2008). As a result, the architecture defined by a designer will be interpreted, used and possibly modified by those who will interact with the service. In some cases, infrastructuring a service means to create a space for conversation, collaboration or confrontation among different actors. This is the case, for instance, of hackathons or public innovation places, such as makers' spaces. In those cases, designers have to create frameworks that specify the rules for action and interaction, the roles of the actors, and the value that can be exchanged in addition to highlighting motivation and engagement issues.

\footnotetext{
${ }^{2}$ The term synchronic representations refers to a representation in which different interactions are synthesised regardless of their sequence in time. A map is a synchronic representation because a number of elements and their interactions are represented in one drawing. In contrast, diachronic representations are representations in which a time sequence is represented; a journey or a storyboard are examples of such a case.
} 
Hackathons, co-creation workshops and design jams are the most common strategies to create spaces for mutual interaction. Such strategies involve very specific events in time that support communities in generating their own value, which designers can directly facilitate. However, open problem solving also concerns platform services, which create permanent or long-lasting physical or virtual spaces for value cocreation, such as that of service platforms. In these cases, certain tools are used to support open problem solving:

- Motivation matrix, which provides a structure of the motivations that would engage different stakeholders in the service. The matrix is a detailed description of the value each stakeholder would provide to the other stakeholders they will interact with in the service system.

- Platform canvasses, which can be used to organise the interaction among different actors in peer-to-peer interactions or in platform services.

- Business model or value proposition canvasses, which help designers specify how value is created, who contributes to it, which channels can be used, and what the financial streams are.

\subsubsection{Service as Infrastructure: Representation Capabilities}

Vision building This is the capability to visualise the logical and organisational infrastructure of a service or a platform by generating perspective views of how the service or platform will be used. In some cases, this capability requires the use of the same representation techniques used for generating architectures, taking into account that the aim of vision building is to communicate values and opportunities to the potential beneficiaries of the service. Therefore, vision building often requires visual or graphic representations to specify how the service structure will contribute to value creation, the possible scenarios of use and also the role, capabilities, and knowledge of each stakeholder.

Tools used for visualisation may include:

- Scenarios: meaning the definition of scenarios for future solutions on the basis of the projection of relevant critical factors. The projection of such scenarios on the present situation can be used to create organisational structures that take into account actors, resources, and motivations in the perspective of the desired future (see Fig. 7.1).

- Video sketching or other narrative techniques that make it possible to communicate aspects such as experiences, expectations or feelings that may not emerge from schematic visions of possible futures.

Common design tools, such as service journeys, can be used to provide future configurations of a service with a high communicative and inspirational power.

Building logical architecture The construction of logical or organisational architectures are often the outcome of a negotiation among different actors. Therefore, the 


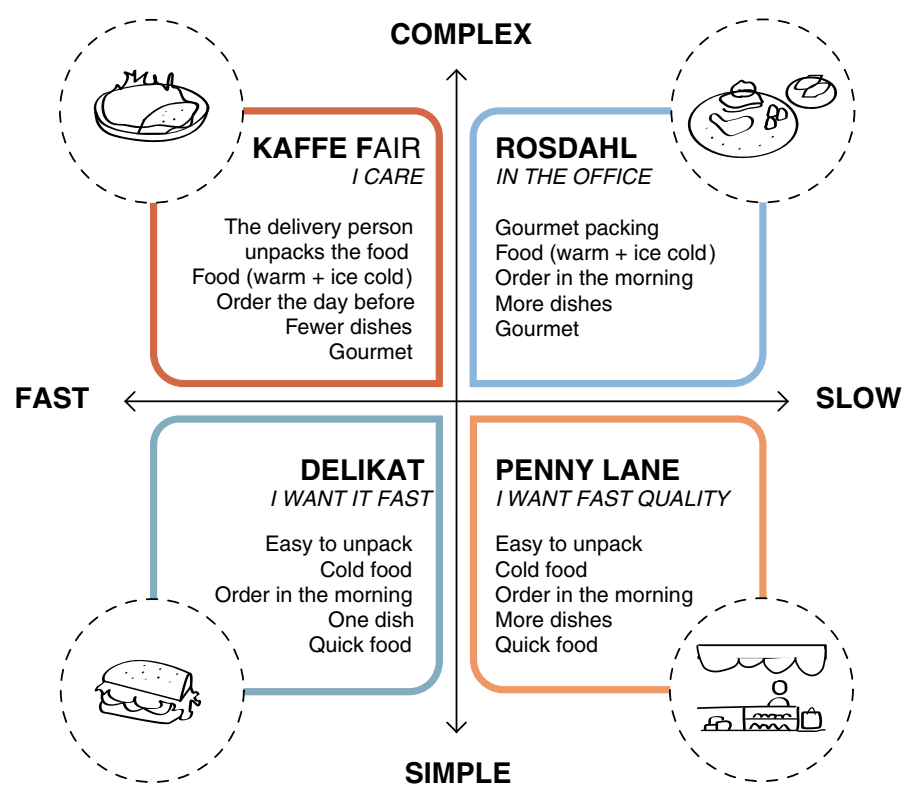

Fig. 7.1 Scenarios for different configurations of a lunch courier service. Adapted from Jonas et al. (2006)

representation of potential architectures for the service is important for the understanding of the stakeholders and for the negotiation of their role. The most common tools used to represent service architectures include:

- Time-related representations, such as service blueprints, that include the sequence of interactions and specify the actors and the channels of such interactions.

- Ecosystem mapping, which highlights the way stakeholders interact with the ecosystem or the benefits and contributions they would get from their participation in the service (Fig. 7.2).

\subsubsection{Service as Systemic Institution: Analytical Capabilities}

Addressing the context Working at the level of systemic institutions involves addressing extremely complex challenges, such as sustainability, social equality or policy-related issues, which are hard to describe or control. Addressing the context in this perspective means applying a systemic perspective and mapping systems with the aim of understanding, or at least making plausible, hypotheses about the way different actors and contextual factors are-or could be-directly or indirectly influencing the behaviour of the system. In addition to the analysis of human and non-human elements, the analysis of the context should also consider the strategies, policies and institutional arrangements that shape the ecosystem. 

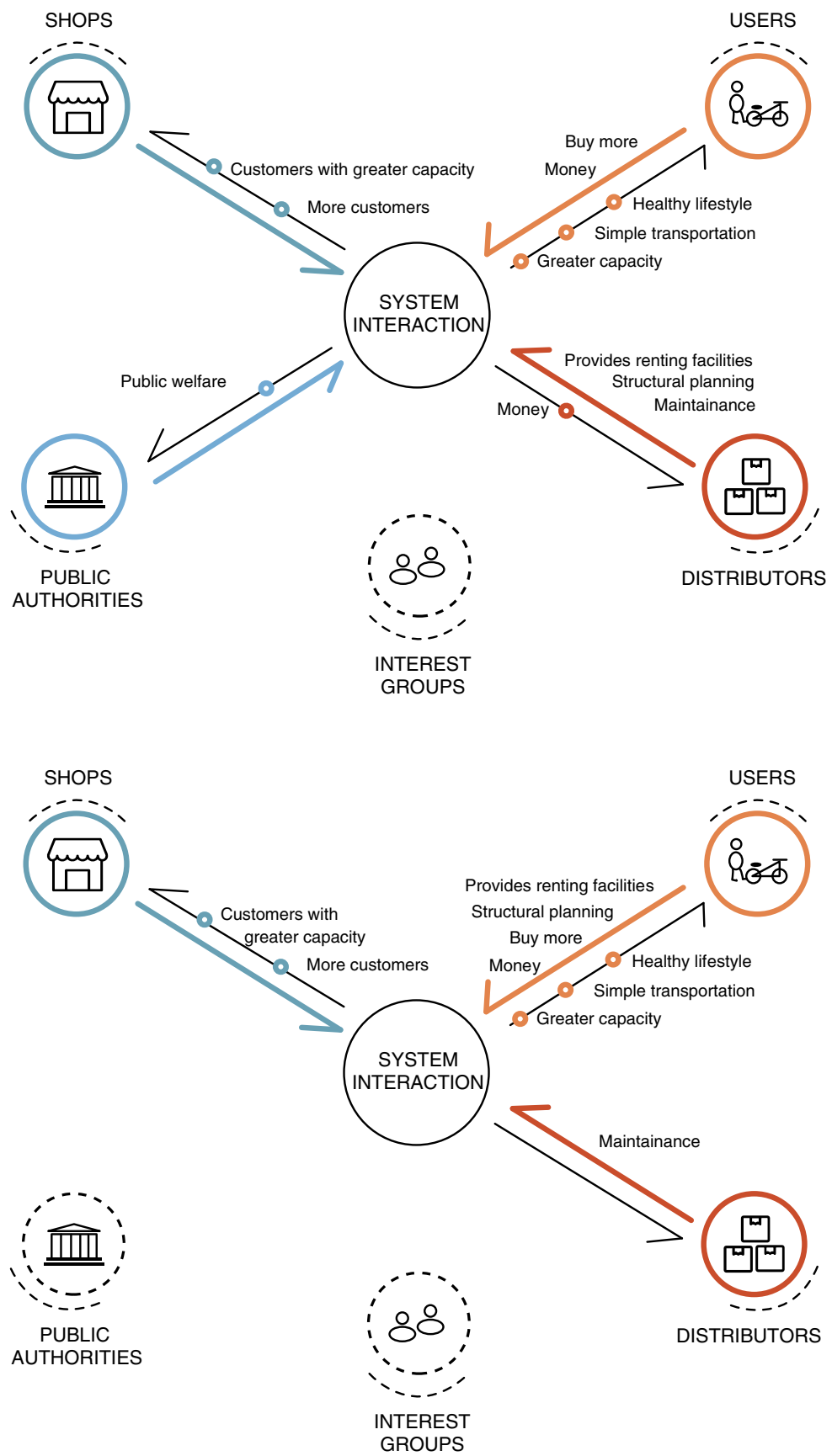

Fig. 7.2 Ecosystem mapping. Mapping the ecosystem can be used to visualise different scenarios/configurations of a service and make hypotheses on the role of each stakeholder. Adapted from Morelli (2006) 


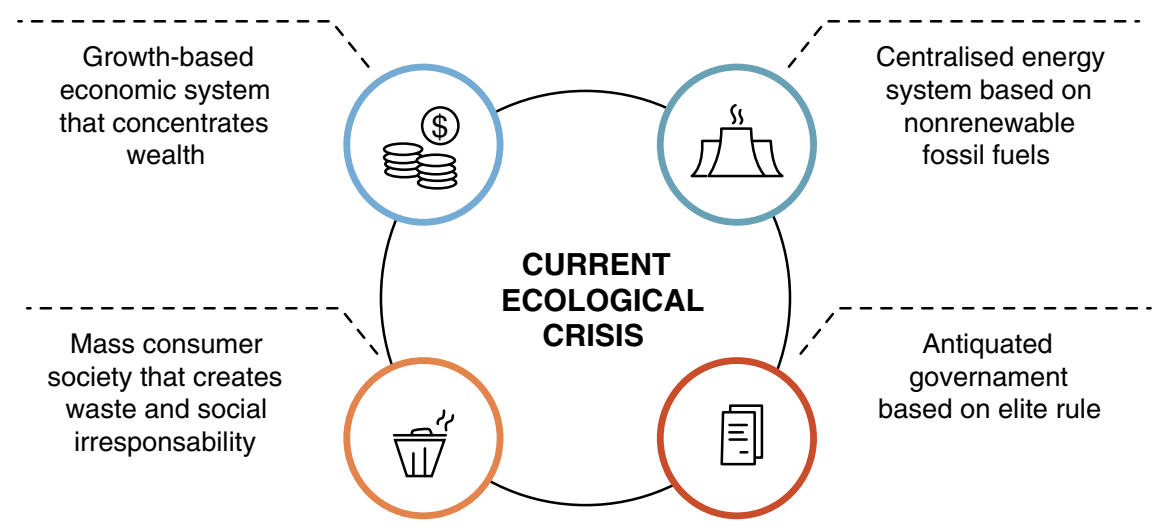

Fig. 7.3 Logical mapping of the context for the current ecological crisis. Adapted from https:// commonstransition.org/toward-regenerative-society-plan-for-rapid-transition\#prettyPhoto

The literature on design interventions to support change in systemic institutions does not specify the methods and tools that have been used to analyse a context. The relatively new role design plays in institutional changes calls for a better definition of specific tools. Systemic contexts, however, can be analysed by:

- System maps, which should include direct interactions between the main stakeholders and interactions with the legal, economic and technological factors. Several types of system analyses map the main issues and current trends and how they influence the present configuration of a system. These analyses are often supported by contributions from sociology, anthropology or economics (Fig. 7.3).

- Critical maps. Maps can also use analytical criteria as coordinates for understanding a systemic landscape and orienting the analysis of the present. The selection of critical factors, for instance, can generate different alternative interpretations of an existing context (Fig. 7.4).

- Moodboards can capture cultural vibes or social aspects that are hard to define in a quantitative description. Moodboards consist of a collection of images that convey general ideas or feelings that derive from a context (the 'character' of a city, or the attitudes of a community, or the genius loci of a place).

\subsubsection{Service as Systemic Institution: Design Capabilities}

Modelling The activity of modelling refers to simulating, visualising or experimenting possible solutions before all the information is available. The simulation of a new configuration of a systemic institution requires taking into account a high level of complexity, which is often hard to control. It is easier to imagine how an interaction can change among two actors in the same service, and it is relatively easier to understand how a service can change. However, it is very hard to imagine 


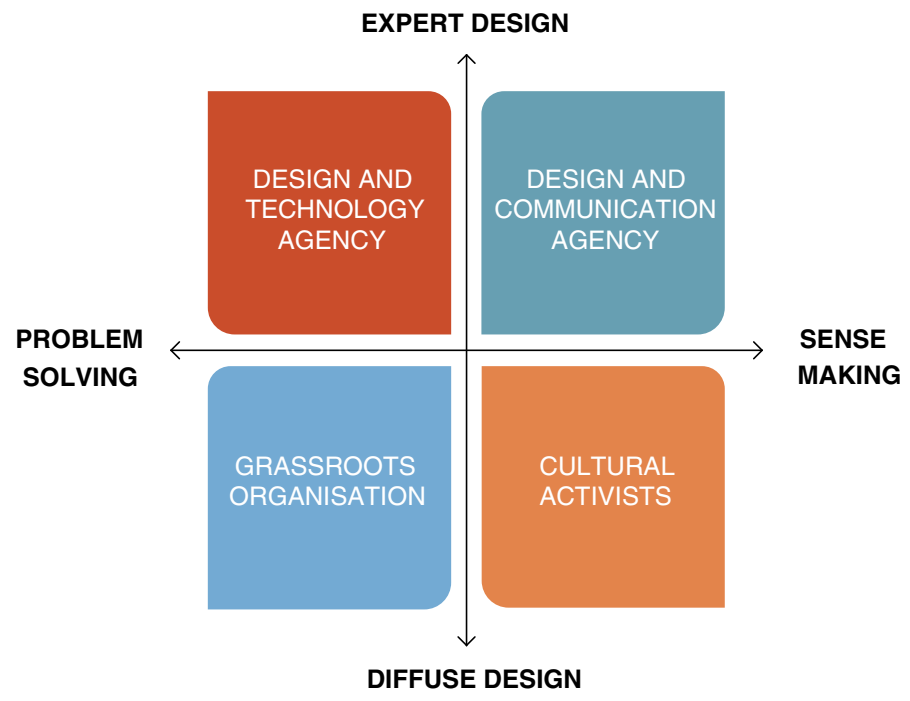

Fig. 7.4 Mapping design agency. Adapted from Manzini (2015)

how an institutional system (a political system, the healthcare system of a country, or cultural institutions) could operate a transition to a new configuration. Designers' capability to model solutions before all the information is available can be useful in those cases because it proposes possible aggregations of different critical factors. Modelling not only represents possible scenarios but also proposes how different actors can play a role using existing resources or contextual conditions within the perspective of desirable transitions.

Here again, tools or methods to support modelling capability at this level of complexity are not adequately documented in the literature because of the relatively new involvement of design as a discipline that deals with change on this scale. Other disciplines work on modelling by using canvasses, often derived or adapted from business model canvasses, to make their proposal for institutional change more concrete. Two tools in particular are often used in this type of modelling work:

- Business model canvases that have been proposed to control different aspects related to systemic changes, including value proposition, key partners, channels, costs and revenues. The business model canvas has been used to analyse business cases rather than systemic changes; however, the idea to use a canvas as a tool to simplify complexity inspired modified versions of the original tool. Canvases have been proposed to address changes in communities (Pfortmüller et al. 2017) or to create institutional infrastructures to involve citizens in the use of open data (Morelli 2018).

- Design-orienting scenarios consisting of the representations of possible and desirable futures in a way that can orient the present design decisions (Manzini et al. 2009). The scenarios are based on the analysis of systemic components and the 
way they will recombine in future changes. Therefore, they offer a narrative view of the possible interplay between stakeholders, technologies, natural elements, social trends and uncertainties. Such scenarios are called 'design orienting' because they provide a framework to orient action in the present. Those visions of the future are therefore not simple projections of the present into the future but rather a critical activity of selecting among different possible futures in order to define preferable directions that can orient present action. They are led by motivations (where we want to go) and include practical indications about the next steps to take towards the preferred indications (Manzini et al. 2009).

Working across different logical levels Designing change in systemic institutions means figuring out broad changes in the social, technical, economic and political landscape. Imagining such change, and in general, figuring out the future has been an activity that has engaged experts in disciplines ranging from economics to literature. One specific contribution designers can offer is in the capability of translating abstract or narrative pictures of possible futures into operative indications on concrete action that also includes parameters for the evaluation of the impact of such actions.

Design capabilities should therefore concern the attitude to visualise possible directions, offering parameters for choosing those that are preferred (see the previous section on modelling) and the opposite attitude to project such long-term perspectives in the short-term future.

The complexity of the present ecosystems requires an active attitude towards the future that can be translated with the articulation of missions that can set the direction for production, distribution and consumption patterns (Mazzucato 2017). Design capability to work at different levels of abstraction could be used to translate such missions into action. A method that is often proposed for managing such a process is the Theory of Change.

The Theory of Change is a way of connecting a long-term transformation with the present by proposing possible 'change journeys' that specify outputs, outcomes and the impact of the proposed change, together with the action that happens in between. Theory of Change is a strategic planning tool that articulates and graphically illustrates the steps that need to be taken to realise a desired goal or impact and the expected results of these steps. It does so by starting from a set of assumptions and hypotheses about the present (theory of problem) and then shows the theorised causal pathways between a project's objectives, its activities, and its expected outcomes and impacts. It says, 'If we take action $\mathrm{X}$, then this will cause effect $\mathrm{Y}$, and this will eventually lead to outcome Z' (Simeone et al. 2019).

\subsubsection{Service as Systemic Institution: Representation Capabilities}

Vision building When visualising and representing large transformations of systemic institutions, designers are not the only ones who are able to contribute 
to generating tangible visions of what the future could look like. Literature, art and cinema are full of realistic representations of this kind. However, the role of designers in this case is to ensure that such visions are usable to orient change, meaning that they are coherent and include critical issues that can be addressed to orient short and long-term change. A purely fantastic vision or utopian/dystopian views of the future proposed by literature, art or cinema have been very effective in triggering debates about the directions in which we want to go, but they are not always useful when used to actively change systemic institutions by generating policies or long-term infrastructural change.

The previous sessions have already mentioned tools, such as the Theory of Change and design-orienting scenarios that can help visualise mission-oriented plans, highlight criteria or impact factors that would translate them into concrete actions.

\subsection{References to the Tools Mentioned in This Book}

The tools mentioned in this chapter and in those previous have been better explained in several toolkits, handbooks or academic papers. We created an additional table, which provides an overview of the main references, taking into account that the continuous production of knowledge on service design tools will likely offer new and more interesting sources. The table is located at this link (https://servicedesig nlab.aau.dk/service-design-capabilities/) and will be further updated after the book has been published.

\section{References}

Arbnor I, Bjerke B (1997) Methodology for creating business knowledge, 2nd edn. Sage, Thousand Oaks and London

Becermen B, Simeone L (2019) Exploring the landscape of service design education: a preliminary review of current programmes in higher education. In: Proceedings of the international association of societies of design research conference, Manchester, 2-5 Sept 2019

Becermen B, Simeone L (2020) Current and future trajectories for service design education: views from educators in academia. In: Proceedings of ServDes2020, Melbourne, 2-5 Feb 2021

Ehn DE, de Götzen A, Simeone L, Morelli N (2020) Do they (know they) need a service designer? An investigation of service design capabilities through the lens of the market. In: Proceedings of ServDes2020, Melbourne, 2-5 Feb 2021

Jonas W, Morelli N, Munch J (2008) Designing a product service system in a social frameworkmethodological and ethical considerations. In: Proceedings of DRS conference, Sheffield, 16-19 July 2008

Kimbell L (2013a) The service innovation handbook: action-oriented creative thinking toolkit for service organizations. BIS Publishers, Amsterdam

Kimbell L (2013b) The social design methods menu. Retrieved from https://www.lucykimbell.com/ stuff/Fieldstudio_SocialDesignMethodsMenu.pdf. Accessed 28 June 2020

Manzini E (2015) Design, when everybody designs. MIT Press, Cambridge 
Manzini E, Jegou F, Meroni A (2009) Design oriented scenarios. Generating new shared version of sustainable product service systems. In: Crul M, Diehl JC, Ryan C (eds) Design for sustainability (D4S): a step-by-step approach. United Nations Environment Program, Delft

Mazzucato M (2017) Mission-oriented innovation policy: challenges and opportunities. UCL Institute for innovation and public purpose working paper (2017-1)

Morelli N (2006) The system around the product: definition of an operative paradigm for industrial design in a systemic context. In: Michael R (ed) Drawing new territories-best of design research. Swiss Design Network, Geneva

Morelli N (2018) Open4Citizens business models and sustainability plans. Open4Citizens project deliverable D4.10. https://open4citizens.eu/wp-content/uploads/2016/01/O4C_D4.10_ 30.06.2018_Final.pdf. Accessed 19 Apr 2020

Morelli N, Tollestrup CHT (2007) New representation techniques for designing in a systemic perspective. In: Proceedings of the second Nordic design research conference, Stockholm, 27-30 May 2007

Pfortmüller F, Luchsinger N, Mombartz S (2017) Community canvas guidebook. The guide to building meaningful communities. https://s3-us-west-2.amazonaws.com/openideo-resources/pro duction/assets/1485.pdf. Accessed 23 June 2020

Polaine A, Løvlie L (2013) Service design: from insight to implementation. Rosenfeld Media, Brooklyn

Sanders EBN, Stappers PJ (2012) Convivial toolbox. BIS Publishers, Amsterdam

Simeone L, Drabble D, Iacopini G, Van Dam K, Morelli N, de Götzen A (2019) Articulating a strategic approach to face complexity in design projects. In: Proceedings of the academy for design innovation management conference, London, 18-21 June 2019. https://doi.org/10.33114/ adim.2019.01.188

Stickdorn M, Schneider J (eds) (2011) This is service design thinking. BIS, Amsterdam

Stickdorn M, Lawrence A, Hormess M, Schneiderr J (2018) This is service design doing. Applying service design thinking in the real world. A practitioners' handbook, 2nd edn. O'Reilly, Sebastopol

Vargo SL, Lusch RF (2004) Evolving to a new dominant logic for marketing. J Mark 68:1-17

Vargo SL, Lusch RF (2008) Service-dominant logic: continuing the evolution. J Acad Mark Sci 36(1):1-10

Open Access This chapter is licensed under the terms of the Creative Commons Attribution 4.0 International License (http://creativecommons.org/licenses/by/4.0/), which permits use, sharing, adaptation, distribution and reproduction in any medium or format, as long as you give appropriate credit to the original author(s) and the source, provide a link to the Creative Commons license and indicate if changes were made.

The images or other third party material in this chapter are included in the chapter's Creative Commons license, unless indicated otherwise in a credit line to the material. If material is not included in the chapter's Creative Commons license and your intended use is not permitted by statutory regulation or exceeds the permitted use, you will need to obtain permission directly from the copyright holder.

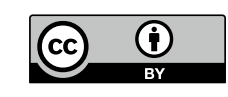

